\title{
SESENGGAK DAN REFLEKSI PANDANGAN DUNIA MASYARAKAT SASAK TERHADAP DIRI DAN LINGKUNGANNYA
}

\author{
Mh. Isnaeni ${ }^{1}$, Nuriadi ${ }^{2}$, Baharuddin $^{3 *}$, Kurniawan Apgrianto $^{4}$, Lalu Nurtaat ${ }^{5}$, Sribagus $^{6}$ \\ University of Mataram \\ *e-mail: \\ muhisnaini@unram.ac.id \\ bahar@unram.ac.id
}

\begin{abstract}
This study is aimed at describing the use of Sesenggak (Sasak Proverbs) by the Sasak people who live in Bunkate and Bonjeruk villages in Central Lombok of West Nusa Tenggara province. The data in this study were derived from interview with the Sasak people especially those who come from Bunkate and Bonjeruk in relation to their understanding on the use and the meanings of Sesenggak as well as the purpose of using Sesenggak in their daily encounters. The research result show that Sesenggak in Sasak community consists of two forms, namely, Sesenggak that consist of two or more lines like limerick in which there are introduction and content and those which don't have introduction. Sesenggak also reflects the characteristics of Sasak people such as self-aware, loyal, responsible, cooperative and selfconfident.
\end{abstract}

Keywords: sesenggak, sasak people, worldview

\section{LATAR BELAKANG}

Masyarakat Sasak adalah masyarakat asli yang mendiami pulau lombok di provinsi Nusa Tenggara Barat. Masyarakat Sasak juga disebut sebagai suku Sasak. Bahasa utama yang digunakan oleh masyarakat Sasak adalah bahasa Sasak. Masyarakat Sasak adalah masyarakat yang kaya akan tradisi, adat istiadat, dan budaya. Sehingga tidaklah mengherankan jika masyarakat Sasak dianggap sebagai masyarakat yang masih sangat kuat memegang adat istiadat, tradisi dan budayanya dalam segala aspek kehidupan baik dalam cara bertingkah laku, berpakaian, berupacara, dan cara berkomunikasi.

$$
\text { Kaitannya dengan cara }
$$

berkomunikasi dalam kehidupan seharihari di dalam masyarakat Sasak di Lombok dikenal adanya kesantunan berbahasa yang ditentukan oleh hubungan antara pembicara dengan lawan bicara. Apabila si pembicara berbicara dengan lawan bicara yang memiliki kedudukan yang lebih tinggi atau orang yang baru dikenal maka si pembicara akan menggunakan ragam bahasa Sasak halus atau yang disebut dengan istilah (base alus) dan apabila si pembicara berbicara dengan lawan bicara yang memiliki kedudukan yang lebih rendah atau terhadap lawan bicara yang memiliki hubungan yang dekat maka digunakan bahasa Sasak biasa atau yang sering disebut (base jamaq).

Di dalam berkomunikasi sehari-hari masyarakat Sasak juga sering menggunakan peribahasa-peribahasa yang dalam bahasa Sasak disebut sebagai Sesenggak. Pemakaian sesenggak ini dilakukan dalam konteks-konteks komunikasi tertentu dalam masyarakat Sasak misalnya ketika ingin menyampaikan suatu pesan tentang nilai moral tertentu kepada orang atau sekelompok orang, dan ketika menasihati seseorang yang dianggap berbuat dan bertindak kurang tepat. Sesenggak adalah salah satu bentuk ungkapan bahasa Sasak yang kaya akan makna dan pesan tentang nilai-nilai kehidupan dan kearifan lokal yang dimiliki oleh masyarakat Sasak tentang kehidupan diri dan lingkungannya.

Dan salah satu komunitas masyarakat Sasak di Lombok yang masih kental mempertahan kan adat istiadat, tradisi, dan budayanya adalah masyarakat 
di desa Bonjeruk dan Bunkate di kecamatan Jonggat, kabupaten Lombok Tengah baik dalam hal upacara adat, tata cara bersikap dan bersopan santun, serta cara berkomunikasi. Oleh karena itu di dalam komunikasi sehari-hari masyarakat Sasak di kedua desa tersebut juga sering ditemukannya penggunaaan Sesenggak (peribahasa Sasak) tersebut. Sehingga penelitian terhadap pemakaian Sesenggak dalam komunikasi sehari-hari masyarakat Sasak di desa Bonjeruk dan Bunkate layak untuk dilakukan sebagai representasi pemakaian sesenggak dalam masyarakat Sasak.

\section{Tujuan}

Berdasarkan latar belakang dan permasalahan di atas, maka tujuan dari penelitian ini adalah: untuk mengidentifikasi jenis-jenis sesenggak yang diucapkan oleh masyarakat Sasak khususnya di desa Bonjeruk dan Bunkate di Lombok Tengah dalam komunikasi mereka sehari-hari dan untuk mengidentifikasi makna sesenggak yang masyarakat Sasak ungkapkan disamping untuk memahami konteks serta tujuan mereka menggunakan sesenggak tersebut sebagai refleksi pandangan dunia yang mereka miliki.

\section{TINJAUAN PUSTAKA \\ Bahasa dan Budaya}

Budaya atau apa yang disebut sebagai culture dalam istilah bahasa inggris memiliki cakupan yang luas. Hal yang pasti adalah setiap masyarakat memiliki budaya tetapi ragam budaya dan tingkat budaya yang dimiliki oleh masyarakat yang satu dengan yang lain berbeda-beda. Kebudayaan suatu masyarakat dapat dipengaruhi oleh faktor alam, agama, kepercayaan, tingkat pendidikan, dan faktor interaksi sosial antara suatu masyarakat dengan masyarakat lain.

Duranti dalam bukunya Linguistic

Anthropology membicarakan tentang teoriteori kebudayaan. Kebudayaan dapat dilihat sebagai agregat pengetahuan, modus komunikasi, atau system partisipasi sosial. Bahasa yang merupakan bagian penting dari kebudayaan dipandang sebagai alat sosial, modus berfikir, dan praktek budaya ( Duranti, 1997:1).

Bahasa dan budaya memiliki keterkaitan yang sangat erat dan saling mempengaruhi. Berdasarkan hipotesis Sapir-Whorf bahwa bahasa menunjukkan pandangan dunia ( worldview ) dari suatu masyarakat, yang selanjutnya akan berpengaruh terhadap modus budayanya karena masyarakatlah yang menjadi pelaku budaya tersebut (Duranti, 1997:56-57 ).

Bahasa juga dapat mencerminkan lingkungan alam dimana masyarakat penuturnya hidup. Hal ini dapat dilihat dari pemakaian leksikon-leksikon tertentu yang dekat dengan kehidupan penuturnya. Misalnya orang Arab memiliki leksikon yang terperinci berkaitan dengan unta dan kurma, sedangkan orang Eskimo memiliki leksikon-leksikon yang banyak berkaitan dengan es dan salju. Demikian pula orang Jawa, Bali, Sasak mampu mengadakan pembedaan terperinci tentang padi dan hal tersebut tercermin dalam bahasanya (Sumarsono, 2008:61).

Disamping lingkungan, nilai-nilai masyarakat dapat pula berpengaruh terhadap bahasa masyarakat itu. Contoh yang jelas misalnya yang menyangkut tabu. Tabu adalah tingkah laku yang menurut kepercayaan terlarang, dianggap asusila atau tidak layak. Di dalam bahasa kata-kata yang ditabukan itu ada, tetapi tidak atau jarang dipergunakan secara terbuka di muka umum. Alat kelamin atau alat vital bagi masyarakat tertentu adalah tabu. Selain itu tabu juga berkaitan dengan kepercayaan. Misalnya orang jawa sering menggunakan kata mbah untuk memanggil roh halus penghuni pohon besar atau orang Bali menyebut tikus hama dengan sebutan jero ketut (Sumarsono, 2008:65).

\section{Bahasa dan Etnik}


Etnik mengacu kepada kelompok yang keanggotaannya berdasarkan asal usul keturunan. Kelompok demikian ditandai dengan ciri-ciri fisik relatif tetap, seperti warna kulit, rambut, hidung, dan sebagainya. Hal lain yang juga dapat dijadikan ciri etnik selain ciri fisik adalah bahasa. Bahasa daerah adalah alat identitas suku. Ada pula pandangan akan adanya hubungan yang tetap dan pasti antara ciriciri fisik suatu etnik dengan sesuatu bahasa atau variasi tertentu (Sumarsono, 2008:67).

Bahasa sebagai ciri pembeda keanggotaan etnik lazim ditemukan di seluruh dunia. Pada umumnya orang akan menyatakan diri sebagai anggota suatu etnik atau suku tertentu dengan ciri penting bahasa ibunya. Orang akan menyatakan dirinya orang Sasak karena bahasa Ibunya adalah bahasa Sasak atau seseorang menyatakan dirinya orang Jawa karena bahasa ibunya adalah bahasa Jawa. Etnik memperhatikan keterpisahan dan identitas melalui bahasa meskipun terdapat ciri-ciri lain seperti agama, sejarah, adat istiadat, dan lain-lain (Sumarsono, 2008:73).

\section{Peribahasa}

Peribahasa adalah kelompok kata atau kalimat yang menyatakan suatu maksud, keadaan seseorang, atau hal yang mengungkapkan kelakuan, perbuatan atau hal mengenai diri seseorang. Peribahasa mencakup ungkapan, pepatah, perumpamaan, ibarat, tamsil ( BaduduZain, 1994)). Peribahasa terdiri dari kumpulan kata atau frasa, klausa atau kalimat yang memiliki struktur susunan yang tetap. Peribahasa merupakan kekayaan pemakaian Bahasa yang di dalamnya mengandung nilai-niai, norma, kearifan, dan pandangan hidup masyarakat pemakainya dengan menggunakan kalimatkalimat yang memiliki arti luas dan merupakan kiasan terhadap maksud tertentu. Di dalam masyarakat Indonesia pada umumnya peribahasa sering diucapkan dalam konteks komunikasi dalam hidup sehari-hari yang digunakan sebagai sarana menyampaikan suatu pesan moral serta menanamkan nilai-nilai kultural dan sosial dalam masyarakat khususnya para generasi muda.

Peribahasa dapat dipahami oleh para pemakainya dikarenakan mereka memiliki latar belakang bahasa dan budaya yang sama. Persamaan ruang lingkup buadaya tersebut merupakan faktor yang krusial di dalam ketersampaiannya pesan dan niai-nilai yang terdapat dalam sebuah peribahasa. Kesaling pahaman (mutual intelligibility) ini adaah syarat mutlak keberhasilan suatu komunikasi. Jadi, pemakaian peribahasa di dalam masyarakat adalah milik bersama yang kalau diucapkan, walaupun hanya sebagian akan dipahami oleh yang mendengar atau membacanya. Contoh peribahasa dalam Bahasa Indonesia jangan kura-kura dalam perahu, jika yang mendengarnya adalah penutur Bahasa Indonesia,maka dia akan tahu bahwa arti dari peribahasa itu adalahjangan pura-pura tidak tahu. Peribahasa jenis ini merupakan pantun yang terdiri atas sampiran dan isi, meski yang diucapkan hanya sampirannya saja tapi orang lain akan tahu apa isinya (www.wikibook.com)

\section{PEMBAHASAN}

\section{Bentuk-Bentuk Sesenggak}

Sesenggak adalah peribahasa Sasak yang dapat dijumpai dalam komunikasi masyarakat Sasak baik dalam percakapan sehari-hari dalam situasi informal maupun dalam situasi formal seperti upacara adat, rapat-rapat desa atau dusun, maupun acaraacara keagamaan di Masjid. Sesenggak dalam Bahasa Sasak ada yang memiliki bentuk seperti pantun yang terdiri dari sampiran dan isi atau pesan dan ada juga yang berbentuk tanpa sampiran yaitu yang hanya terdiri dari isi. Biasanya Sesenggak yang memiliki sampiran biasanya terdiri dari dua atau tiga baris, dimana baris pertama adalah sampiran dan baris kedua 
adalah isi. Sedangkan Sesenggak yang hanya berupa isi hanya terdiri dari satu baris saja.

Adapun beberapa contoh sesenggak yang memiliki sampiran adalah sebagai berikut: 1. Lile-lile kelewe

1. Lile-lile laguk mele

2. Berugaq bawun batu Muq ndek uah gitak ndekku nyadu

3. Empat lime lepang tunjuk Berat ime mesang cucuk

4. Olah-olah daun are Solah-solah jari dedare

Tokol ngengkeng sogol entut Adapun contoh-tontoh sesenggak yang tidak memiliki sampiran adalah sebagai berikut:

1. Ajah diriq baruq ajah dengan

2. Angkat ende bani betatu

3. Bareng anyong saling sedoq

4. Bis entan bis kelampan

5. Cobaq juluk baruk ngalah

6. Dendeq abot pantoq gong

7. Jari eleh joq segare doang

8. Kedung basaq payu mandiq

9. Kebon jari lendang, lendang jari kebon

10. Ndaq girang pataq paren dengan

11. Ndaq kerisaq pager dengan, kerisaq juluk pager mesaq

Dari contoh-contoh sesenggak diatas, terlihat bahwa jumlah sesenggak yang tidak memiliki sampiran (terdiri dari satu baris) jauh lebih banyak dibandingkan sesenggak yang memiliki sampiran atau yang terdiri dari dua baris atau lebih. Hal ini mungkin dapat disebabkan karena sesenggak yang tidak memiliki sampiran memiliki bentuk yang lebih sederhana sehingga lebih mudah untuk diingat dan digunakan dalam percakapan.

\section{A. Makna dan Refleksi Pandangan Dunia Masyarakat Sasak dalam Sesenggak}

Sesenggak atau peribahasa Sasak adalah perwujudan cipta, rasa, dan karsa masyarakat Sasak yang di dalamnya terkandung pesan moral, nilai budaya, serta kearifan lokal yang dimiliki oleh masyarakat Sasak sebagai masyarakat yang beradab dan berbudaya. Sesenggak adalah produk budaya dalam bentuk Bahasa yang di dalamnya tercermin konsep berfikir dan pandangan dunia masyarak Sasak tentang diri dan lingkungannya yang menjadi karakteristik masyarakat Sasak dalam bertindak dan berperilaku.

Karakteristik masyarakat sasak yang tercermin dalam Sesenggak diantaranya adalah:

\section{Masyarakat Sasak adalah masyarakat yang memiliki rasa tanggung jawab}

Masyarakat Sasak adalah masyarakat yang penuh tanggung jawab, yang berani menghadapi segala permasalahan yang harus dihadapai sebagai konsekuensi dari perbuatan atau tindakan yang dilakukan, melaksanakan kewajiban yang menjadi tugas yang diembannya. Karakteristik tanggung jawab yang dimiliki oleh masyarakat Sasak ini dapat tercermin dari Sesenggak "Angkat ende bani betatu" yang maknanya berani berbuat harus berani menerima konsekuensi, resiko, atau akibat dari perbuatannya itu. Sesenggak "Angkat ende bani betatu" secara harfiah berarti mengagkat ende (perisai dalam peresean) berani terluka. Hal ini menunjukkan sikap dan perilaku tanggung jawab dimana ketika seseorang berani mengagkat ende yang artinya berani ikut dalam tanding peresean maka dia harus berani menerima risiko dari tanding peresean itu yaitu berani mendapatkan luka akibat dari pukulan lawan tanding.

Sesenggak lain yang juga merefleksikan sifat tanggung jawab dalam masyarakat Sasak adalah "Kedung basaq payu mandiq". Sesenggak ini secara harfiah berarti sudah kadung basah sekalian mandi. Sesenggak ini mencerminkan rasa tanggung jawab terhadap suatu perbuatan yang sudah dilakukan atau suatu keadaan 
yang sudah terjadi yang harus dihadapi apapun risiko yang akan diterima. Sesenggak "kedung basaq payu mandiq" mencerminkan sikap tanggung jawab yang dimiliki masyarakat Sasak terhadap perbuatan yang sudah dilakukan serta berani menghadapi permasalahan yang dihadapi dengan segala akibat yang akan terjadi.

\section{Masyarakat Sasak adalah masyarakat yang memiliki kesetiakawanan/ kebersamaan}

Kesetiakawananan adalah salah satu sifat atau nilai moral yang dipegang oleh masyarakat Sasak. Kebersamaan dalam menghadapi segala permasalahan dalam hidup adalah salah satu ciri masyarakat Sasak yang sebagian besar hidup di daerah pedesaan. Tradisi betulung atau gotong royong dalam melakukan berbagai kegiatan baik kegiatan bersama seperti membersihkan lingkungan, membangun tempat peribadatan (masjid), atau mengadakan upacara keagamaan maupun kegiatan peribadi seperti begawae ( pesta ) atau roah (syukuran) dilakukan secara Bersama-sama dalam masyarakat Sasak.

Salah satu sesenggak yang
mencerminkan
kebersamaan/kesetiakawanan ini adalah "Bareng anyong saling sedoq" yang arti harfiahnya adalah sama-sama larut saling angkat/ambil. Hal ini merefleksikan kebersamaan dalam kondisi apapun; ketika menghadapi permasalahan harus saling membantu dan mendukung serta ketika mendapatkan keberuntungan maka harus saling bagi agar sama-sama merasakan baik kesusahan maupun kesenagan.

\section{Masyarakat Sasak adalah masyarakat yang memiliki rasa malu dan mawas diri}

Rasa malu dan mawas diri adalah salah satu karakteristik masyarakat Sasak yang terefleksikan dalam Sesenggak yang dimilikinya. Masyarakat Sasak memiliki nilai tidak suka atau malu ikut campur terhadap urusan orang lain kalau tidak diminta untuk ikut campur dalam urusan orang lain serta tidak mudah menilai orang salah karena suatu kekeliruan yang dimiliki. Sesenggak Sasak yang mencerminkan sikap ini adalah "Ajah diriq baruq ajah dengan" yang artinya ajari diri sendiri dulu baru mengajar orang lain dan sesenggak "Ndaq kerisak pager dengan, kerisak juluk pager mesaq" yang artinya jangan perbaiki pagar orang lain, perbaiki dulu pagar diri sendiri.

Kedua sesenggak di atas mencerminkan perilaku masyarakat Sasak yang mengutamakan introspeksi diri dan memperbaiki kesalah diri ketimbang hanya melihat kesalahan orang lain. Hal ini juga dapat diartikan bahwa masyarakat Sasak juga memiliki rasa malu terhadap diri dan lingkungnnya. Malu untuk ikut campur dalam urusan orang lain dan menghakimi orang lain serta malu terhadap dirinya karena kesalahan dan perbuatannya atau malu untuk melakukan sesuatu yang bertentangan dengan nilai moral, etika, dan ajaran agama yang dianutnya.

\section{Masyarakat Sasak adalah masyarakat yang tidak pantang menyerah dan berani}

Ciri lain masyarakat Sasak yang terlihat dari property budaya dan bahasanya yang berbentuk Sesengggak adalah masyarakat sasak memiliki keberanian dalam melakukan sesuatu dan tidak mudah putus asa atau menyerah. Adapun sesenggak yang dapat merefleksikan hal ini adalah "Cobaq juluk baru ngalahan" artinya coba dulu baru mengalah. Sesenggak ini memberi pesan bahwa kita harus berani mencoba suatu tantangan walaupun harapan untuk berhasil mengatasi tantangan tersebut nampak kecil atau dalam kata lain jangan kalah sebelum bertanding. Hal ini menunjukkan keberanian untuk mencoba. 
Sesenggak lain yang juga mencerminkan keberanian dan pantang menyerah adalah " Dendeq abot pantoq gong" yang arti harfiahnya adalah jangan malas memukul gong. Sesenggak ini memberikan pesan bahwa orang harus berani bertanya apabila tidak tahu tentang sesuatu apapun itu baik tempat, cara, aturan, dan lain-lain. Sesenggak ini juga menunjukkan nasihat untuk selalu belajar dan menambah pengetahuan tentang segala hal yang belum diketahui dengan berguru atau bertanya kepada orang yang memiliki pengetahuan dan ilmu di bidang tersebut.

\section{Masyarakat Sasak adalah masyarakat yang memiliki kesungguhan \\ Bersungguh-sungguh dalam} berbuat adalah satu ciri lain orang Sasak yang dapat dilihat dari Sesenggak yang dimilikinya. Sifat ini dapat dilihat dalam sesenggak "Bih entan bih kelampan" yang arti literalnya adalah habis cara habis perjalanan. Sesenggak ini mencerminkan kesungguhan ketika melakukan sesuatu dengan segenap cara dan usaha yang mungkin dilakukan. Sesenggak ini memberikan pesan bahwa orang tidak boleh setengah-setengah dalam berbuat, sesuatu harus dilakukan dengan cara serius dan sungguh-sungguh agar hasil yang maksimal dan optimal dapat diperoleh.

\section{KESIMPULAN DAN SARAN}

Sesenggak adalah kekayaan hasanah budaya dan Bahasa masyarakat Sasak yang di dalamnya terkandung pesan moral, nilai-nilai, pandangan dunia masyarakat terhadap diri dan lingkungannya oleh karena itu Sesenggak dapat dijadikan sebagai salah satu sarana untuk memahami karakteristik Masyarakat Sasak. Sesenggak digunakan dalam kehidupan masyarakat sehari-hari untuk menyampaikan pesan moral tertentu, memberikan nasihat dan wejangan kepada orang lain serta sarana untuk introspeksi diri.

Pemahaman dan pemakaian Sesenggak pada zaman sekarang ini sudah semakin tergerus oleh istilah-istilah dalam Bahasa lain sebagai akibat dari globalisasi dan perkembangan teknologi informasi yang sangat pesat terutama pada generasi milenial. Oleh karena itu tindakan nyata untuk melestarikan sesenggak sasak ini perlu untuk dilakukan.

\section{DAFTAR PUSTAKA}

Badudu.J.S,Zain.S.M.1994. Kamus Umum Bahasa Indonesia.Jakarta. Pustaka Sinar Harapan.

Duranti. A. 1997. Linguistic Anthropology. Cambridge. Cambridge University Press.

Sumarsono.2008.Sosiolinguistik.Yogyakar ta. Pustaka Pelajar

http//:www.wikibook.org 